\title{
The power of new media Bestnine Instagram in creating a popular culture for creative industry workers
}

\section{The study of the popular Instagram Bestnine application among the Illustrators}

\author{
Florens Debora Patricia \\ Visual Communication Design \\ Institute of Bussiness and Informatics Stikom Surabaya \\ Surabaya, Indonesia \\ flayravenz@gmail.com,florens@stikom.edu
}

\begin{abstract}
Bestnine Instagram is one of the most popular New Media today. The Enchantment of Bestnine is not only interesting among the elite, but has also spread to industrial workers such as; musicians, artists, illustrators and animators. According to a survey by the American Paw Research Center, the level of using Instagram in 2015-2016 has risen to $51 \%$. This study aims to examine the process of popularity Bestnine Instagram using Everett Rogers's, theory Diffusion Innovation, with qualitative method focusing on the literature review, documentation, and exploration. The result is scheme new idea and technology are dispersed in cultural containers and shaping social change that spawned a popular cultural trend.
\end{abstract}

Keywords—new media; Bestnine; Instagram; popular culture; illustrator

\section{INTRODUCTION}

Media in carrying out its function, besides as the dissemination of information and entertainment, it is also as the institution of creator and market control of commodity product in a social environment. One of the most popular media in this era is social media. Online social media is a media designed to facilitate interactive social interaction easily with internet-based technology that change the way of information dissemination from previous broadcast media monologue (one to many audiences to social media dialogue (many audiences to many audiences). Online social media contributes to the creation of democratization on the information and science that changed the behavior of the audiences from consuming the content to producing the content. The strength of online social media is constructing the reality of the media which is the reality that is constructed based on the system managed by the media aimed to achieve financial benefits from the public who consume all types of offered commodities. Popular culture emerges and defends the purpose of media (a capitalist ideology) and the behavior of public consumption. [1] In the case of popularizing a cultural product, the media acts as a disseminator of information as its function and the formation of public opinion which developed into the homogeneity of opinion and desire. Consequently, everything produced by a media will be accepted by the public as a value, in this case the cultural value. The popular cultural value will continue to create and display a new form of culture, as human civilization continues to transform with its environment following the times.

One of the most popular online social media in this millennial era besides Facebook is the Instagram. The popularity of Instagram is arising, along with the increasing number of the users. According to CEO Instagram, Kevin Systrom, the number of application users has reached 700 million. Kevin stated that it had been known that there were 100 million new users in Instagram in the last four months. Instagram had 600 million users in December last year. [2] Instagram can be defined as a mobile application based iOS, Android and Windows Phone where users can shoot, edit and post photos or videos to Instagram's main page and other social medias. Instagram was originally developed by a startup named Burbn, Inc. that was managed by Kevin Systrom and Mike Krieger. In their hands, Instagram is successfully made a huge social network; later Facebook, gave up so it willed to bought Instagram for \$ 1 billion, the acquisition was on April 9, 2012. Instagram is getting popular in society, besides popular in the elite, Instagram is also very popular among the workers in creative industries, such as musicians, artist, illustrator and animator. Instagram has several features, such as camera, editor, tag and hashtag, caption, and integration to social networking. And its latest feature which is popular nowadays is Bestnine. Bestnine is an Instagram application that works to collect and display the best collage of photographs for a year. Bestnine can be accessed through the portal of https://2014Bestnine.com/ to review photo collage of Instagram account during 2014, portal https://2015Bestnine.com/ to review photo collage of Instagram account during 2015, https : //2016Bestnine.com/ to review photo collage of Instagram accounts during 2016, and https://2017Bestnine.com/ to review photo collage of 
Instagram accounts during 2017. Or Bestnine can also be personally made by account users by collecting 9 memorable photos and re-uploaded to Instagram users' private account by adding hashtag \#2017Bestnine [3].

Beside popular in the new users, Bestnine also gradually become a trend among creative illustrators today. The popular expert illustrators, such as Lois van Baarle, Fran Solo, Griselda Sastrawinata and Goro Fujita took part in using Bestnine on Instagram. These creative people collect their best works for a year and put them back on their Instagram account. Then, the trend became viral and followed by the other illustrators and became popular culture on Instagram since last few years. Although there were some illustrators who are in the pros and cons in using Bestnine, many illustrators thought that Bestnine means as the reflection of their works, which became a benchmark to be able to work better in the next year. It is the evidence of how Bestnine Instagram has shaped the characteristics of nowadays modern society. The phenomenon of Bestnine Instagram has proved how powerful media in manipulation the creative people in the industrial world, without popular culture, media never been existed.

\section{METHOD}

This study used literature review, documentation, and exploration to know how far Instagram Bestnine popular among the creative workers, especially for the Illustrator. The approach used in this research was the communication paradigm of Everett Rogers, the theory of Innovation Division $^{4}$. This theory recognized that a new idea and technology are dispersed in a cultural container. This theory was popularized by Everett Rogers in 1964 through his book "Diffusion of Innovations." Rogers defined diffusion as the process by which an innovation is communicated through various channels and time periods within a social system. The use of innovation diffusion theory is strengthened by Lester who described the characteristics of new media concepts: digital, interactive, hypertextual, virtual, network, and simulation, thus becoming a popularity benchmark of new media as the facilitator in channel model in taking innovation decision formed of stages; knowledge-persuasion-decisionimplementation-confirmation.

\section{DISCUSSION}

\section{A. Instagram}

Instagram was originally developed by a start-up named Burbn, Inc. managed by Kevin Kevin Systrom and Mike Krieger. Burbn, Inc is a start-up technology that focused on developing applications for HTML5-based mobile phones used for checking in locations, earning points for hanging out with friends, posting photos and updating status. At first, Burbn, inc. had many foci in HTML5 Mobile (Hiper text markup language 5), but both CEOs (Chief Executive Officers) Kevin Systrom and Mike Krieger recently focus on one thing [4]. Welcome To Instagram, this is the opening written by Kevin Systrom and Mike Krieger on his official blog on October 6, 2010, which marked the coming of revolutionary photo sharing Instagram Application. In the start-up built by them, Burbn, Inc., Kevin Systrom and Mike Krieger worked hard to create a photograph-based social networking service to suit on their willingness. Steve Jobs (the founder of Apple), Bill Gates (the founder of Microsoft), Mark Zuckerberg (the founder of Facebook), Matt Mullenweg (the founder Wordpress), Google and the others are world class technological innovators who have developed revolutionary products since they were young [4].

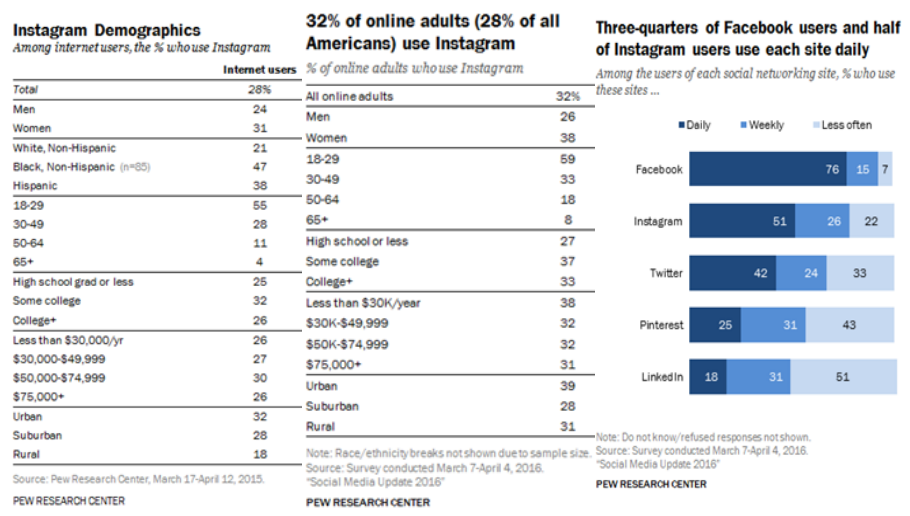

Fig. 1. The level of using Instagram based on American Paw Research Center in 2015-2016

According to Bambang, Instagram is an application from Smartphone specifically for social media which is one of the digital media that has a function similar to Twitter, but the difference lies in taking pictures or place to share information of the users. Instagram provides some ideas for its users. Further, it can enhance the creativity because Instagram has a feature, such as making photos become more beautiful, more artistic and better [4].

Instagram has several features such as camera, editor, tag and hashtag, caption, and integration to social networking. The latest popular feature is Bestnine. Bestnine is an Instagram application worked to collect and display the best collage of photographs for a year. Bestnine can be accessed through the portal https://2014Bestnine.com/ to review photo collage of Instagram account during 2014, portal https://2015Bestnine.com/ to review photo collage of Instagram account during 2015, https : //2016Bestnine.com/ to review photo collage of Instagram accounts during 2016, and https://2017Bestnine.com/ to review photo collage of Instagram accounts during 2017. Further, Best Nine can also be made privately by account users by collecting 9 memorable photos and re-uploaded to Instagram users' private account by adding hashtag \#2017Bestnine [4].

\section{B. New Media}

New media-related studies, such as the Nell Haynes' study entitled, "Social Media in Northern Chile" examined how Chilean used social media in daily life. Haynes emphasized that by having social media and using it appropriately, it can enhance creative resources for society; for example, the recent 
popular new media, Instagram. Haynes categorized Instagram as a new media that is familiar to the millennial generations, because of its easy mode. The following results of a survey conducted by Paw Research Center in the United States about the level of the use of Instagram which had been developed significantly [5].

Lister in his book New Media: A Critical Introduction illustrated the concept characteristics of new media; digital, interactive, hypertextual, virtual, network, and simulation [6]. (1) Digital, it designed with combining audio and visual, with the speed and frequency of displays and active responses, in Instagram Bestnine; (2) Interactive, it enables Bestnine users in Instagram to interact each other and directly involved in the change of images or text they access; (3) Hypertext. The text which capable of connecting other text outside in existing text. It allows Bestnine in Instagram to read text non-sequentially as like the old media. I start from wherever the users want; (4) Networks, this context is the infinite dimensions in the Instagram Bestnine application. This application can be downloaded through google store, apps store or by using website services. (5) Virtual, the virtual world created by the illustrator through his Instagram account; (6) Simulations, the interactions among illustrators with fans, or the other users, in the form of comments, like comments, and likes on the uploaded illustrator's photos in his Instagram account. Furthermore, the concepts of new media characteristics that then effect to channel model of innovation in decision-making process initiated by Everett Rogers formed with knowledge persuasion - decision - implementation - confirmation [7].

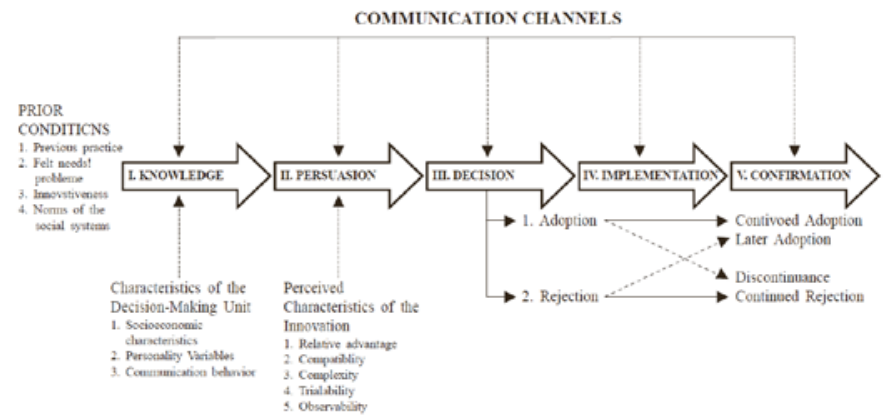

Fig. 2. Model of Innovation Decision Making Process (Rogers, 1983)

The knowledge, defined as the stage where a person or in this case the illustrator, has no information about Bestnine application in Instagram and its benefits. To get information about the innovation related to the application, the illustrator can get it based on the recommendation of his colleagues who have been using the Bestnine application, or by some online media that published the news about Bestnine application. This step is also influenced by some characteristics in decision-making of the illustrators, they are (1) socioeconomic characteristics. As their profession as the illustrators, they formed a network to increase their income, dignity as professionals; (2) Values of personality (environment, emotions, creativity, ideas) and (3) Communication patterns, among peers, families and in community life.
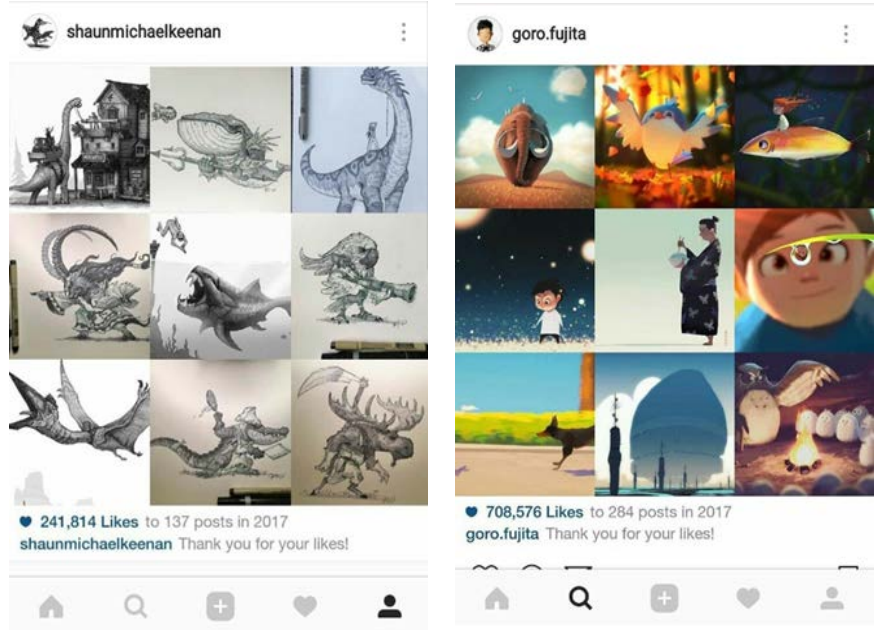

Fig. 3. Screen Shot of Shaun Michael Keenan's Instagram account (left) and Goro Fujia's Instagram account (right) who using Bestnine apps.

Persuasion, at this stage, where the illustrator is interested in Bestnine application and actively seeking for information or the details about Bestnine through Instagram or the other online media. The second phase is more emphasizing on the level of interest at the users' thought in Bestnine applications, through innovation. The innovation is related to the characteristics of the innovation itself, such as (1) The strenght of innovation in Bestnine application used by illustrators, (2) The compatibility of Bestnine, so it is easily accepted among the illustrators, (3) Bestnine complexity, in terms of its use, whether it is easy or too complicated. (4) Bestnine can be quickly applied by visiting https://2017Bestnine.com/ website. Then, the illustrator types his Instagram account name in the space provided, and press the enter button. Finally, the illustrator can see directly the collage of his photographs works for a year, and (5) it can be reviewed, in the context of illustrators' purposes, they can directly re-check the photo collage by using the Bestnine application via the website or by downloading via Google apps and Apple store.

Decision. At this stage, the illustrator takes the innovation concept from Bestnine, thinks the advantages / disadvantages by using Bestnine innovation and decides whether to adopt or to reject Bestnine website application innovation. In this context, many other illustrators, Griselda Sastrawinata and Lois van Baarle, envolved in the Bestnine phenomenon by creating their own version creatively. The illustrators made their own photo collage, numbered their 9 photos, and uploaded them to their Instagram account by adding hashtag \#Bestnine2017. 


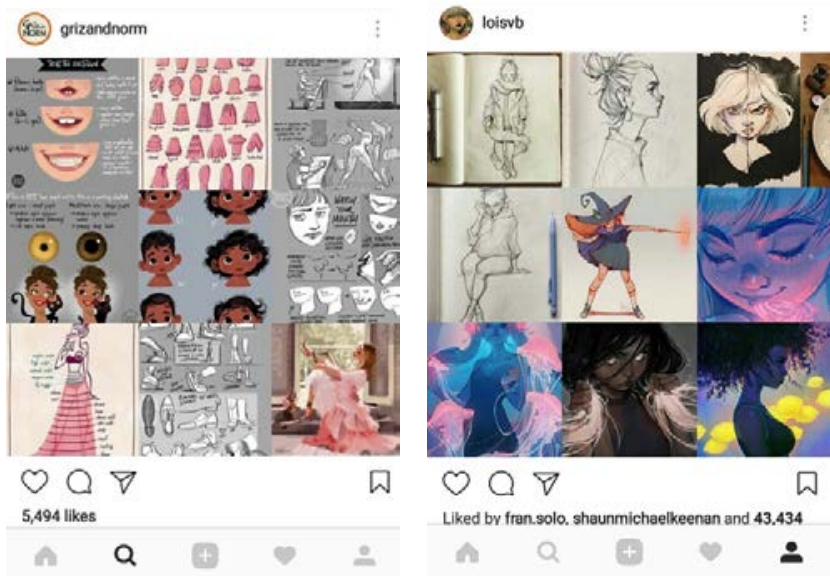

Fig. 4. Screen Shot of Griselda Sastrawinata Instagram account (left), and Lois van Baarle Instagram account (right) who using hashtag \#Bestnine2017.

Implementation. In the using Bestnine, each illustrator has its own characteristics such as some illustrators are still using the Bestnine application through the process of downloading websites, Google store, Apple store and creating personally using hashtag \#Bestnine2017, each innovation is different depending on the situation. In this stage, the illustrator determines the use of the innovation and searches for more information about it. Then, a person will then seek for the justification for their decisions. The possibility is a person will change the decision that was previously refused, to accept innovation after the evaluation.

Confirmation. For this case, confirmation builds trend or phenomenon is easily chosen and followed by an illustrator who wants to show to his fans, clients and the community about a lifestyle of a popular person nowadays. Someone who closely follows the development of social media, indirectly construct his self as someone with a modern lifestyle who always follows the trend. It shows that in the modern world, lifestyle helps to determine the attitudes and the values and shows social status and personal identity. Therefore, the society makes the social construction and follows the lifestyle of someone who has an interesting profession because it can be accepted by the community and chosen by teenagers as well as a trend called popular culture.

\section{REFERENCE}

[1] S. Dominic, Popular Culture: Introduction towards the Popular Culture Theory. Bandung: Jejak Publishing, 2016.

[2] L. Andina, "Instagram had 700 million users”, liputan6, 27 April 2017. [Online].

Available: https://www.liputan6.com/tekno/read/2933354/instagram-kantongi-700juta-pengguna [Accessed: 20 April 2018].

[3] W. Bambang, "What is instagram, features and how to use it?", dailysocial, 17 September 2015. [Online]. Available: https://dailysocial.id/post/apa-itu-instagram [Accessed: 28 April 2018].

[4] A. D. Bambang, Instagram Handbook Tips for Handphone Photography. Jakarta: Media Kita, 2012.

[5] H. Nell, Social Media in Northern Chile. London: UCL Press, 2016, pp. 46-68.

[6] Lister, et al. New Media: A Critical Introduction. NY: Routledge, 2009. pp. 13-16.

[7] R. M. Everett, Diffusion of Innovations, New York: The Free Press, 1986, pp.189-190. 